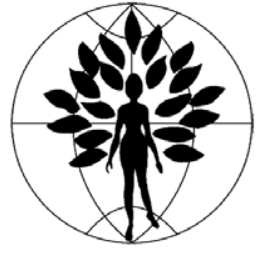

www.figo.org available at www.sciencedirect.com

www.elsevier.com/locate/ijgo

CLINICAL ARTICLE

\title{
Perception and use of complementary and alternative medicine among gynecologic oncology care providers
}

\author{
Jennifer M. Rhode ${ }^{a}$, Divya A. Patel ${ }^{b}$, Ananda Sen ${ }^{c}$, Veronica L. Schimp ${ }^{d}$, \\ Carolyn M. Johnston ${ }^{\text {b }}$, J. Rebecca Liu ${ }^{\text {b,* }}$
}

${ }^{a}$ Gynecologic Oncology Services, Wright-Patterson Air Force Base, Ohio, USA

b Department of Obstetrics and Gynecology, University of Michigan, Ann Arbor, Michigan, USA

' Center for Statistical Consultation and Research, University of Michigan, Ann Arbor, Michigan, USA

d Department of Obstetrics and Gynecology, Division of Gynecologic Oncology, Wayne State University, Detroit, Michigan, USA

Received 29 April 2008; received in revised form 2 June 2008; accepted 3 June 2008

\section{KEYWORDS}

Complementary and

alternative medicine;

Gynecologic oncology;

Medical oncology

\begin{abstract}
Objective: To determine general attitudes and approaches to complementary and alternative medicine (CAM) among physicians who care for gynecologic oncology patients. Methods: Surveys were mailed to members of the Society of Gynecologic Oncologists and the Michigan Oncology Group. Physicians were asked to rate their general attitude toward CAM. Results: Surveys were obtained from 462 physicians. Gynecologic oncologists and female physicians were more likely to have positive attitudes toward CAM, and to believe that clinical care should integrate conventional and CAM practices, compared with other oncologists and male physicians. Conclusion: Discrepancies exist among oncologists regarding attitude and use of CAM in their practice. Education of physicians regarding the safety and efficacy of CAM modalities may ultimately improve patient care.

(ㄷ) 2008 International Federation of Gynecology and Obstetrics. Published by Elsevier Ireland Ltd. All rights reserved.
\end{abstract}

\section{Introduction}

Complementary and alternative medicine (CAM) includes medical interventions that are not taught widely in medical

\footnotetext{
* Corresponding author. Department of Obstetrics and Gynecology, Division of Gynecologic Oncology, 1500 E. Medical Center Drive, 4130 CCGC, Ann Arbor, MI 48109-0936, USA. Tel.: +1 734936 3024; fax: +1 7347647261.

E-mail address: rliu@med.umich.edu (J.R. Liu).
}

schools or are not generally available in hospitals in the United States [1]. The major categories of CAM as defined by the National Center for Complementary and Alternative Medicine (NCCAM) include: alternative medical systems; mind-body interventions; biologically-based therapies; manipulative- and body-based methods; and energy therapies [2]. The use of CAM among the general population continues to increase [1], and $49.6 \%$ to $66 \%$ of gynecologic oncology patients in the United States have used CAM [3,4]; this is consistent with previous reports that indicate that use of CAM is most prevalent among female cancer patients [5]. 
The general perception of CAM among physicians caring for gynecologic oncology patients in the United States is unclear. Although patients' use of CAM is prevalent in industrialized countries $(40 \%-70 \%)$ [6-8], there have been few studies to evaluate clinical oncologists' perception and use of CAM. National surveys conducted in Japan and Brazil indicated that the majority of oncologists $(80.7 \%-82 \%)$ believed that CAM products were ineffective against cancer, and would not promote the use of CAM $[6,9]$. Data from a smaller study conducted within the MD Anderson Cancer Center, Texas, USA, indicated that oncologists were significantly less likely to believe that CAM could provide a cure, extend life, improve immunity, or improve quality of life compared with the patients [10].

Among patients who use CAM, $19 \%-42 \%$ do not disclose its use to their oncologist [11]. There are several CAM therapies that offer potential benefits for cancer patients; however, there are others that are ineffective, or that place patients at risk for direct adverse effects. For example, the use of acupuncture and acupressure has been shown to significantly improve cancer-related fatigue [12]. In contrast, it is reported that symptomatic hypercalcemia can develop in cancer patients taking supplemental calcium, vitamin $D$, or shark cartilage preparations [13]. Thus, it is essential that oncologists have access to authoritative information regarding CAM therapies to advise patients responsibly.

Formal implementation of medical education related to CAM did not occur on a national basis until 2002-2003, when the Education Working Group of the Consortium of Academic Health Centers for Integrative Medicine (CAHCIM) established medical school curriculum guidelines [14]. The majority of practicing gynecologic oncologists completed medical training prior to establishment of the CAHCIM guidelines, and therefore formal CAM training among physicians caring for this patient population is rare. The present study was conducted to determine the general attitudes and approaches to CAM among physicians who care for gynecologic oncology patients.

\section{Materials and methods}

The survey used in the present study was approved by the Institutional Review Boards at the University of Michigan Medical School (IRBMED), St Josephs Mercy Hospital (Ann Arbor, Michigan), and Karmanos Cancer Center (Detroit, Michigan). Completion of the survey was considered consent to participate, and no direct identifiers were included in the surveys.

A self-administered anonymous questionnaire was mailed to all full members of the Society of Gynecologic Oncologists (SGO) residing within the United States during the year 2004$2005(n=574)$ and all members of the Michigan Oncology Group (MOG, $n=371$ ). Questionnaires were adapted from previously published studies $[8,9,15-17]$. All physicians received the same cover letter and questionnaire with no monetary or other incentive for participation. Because the initial response rate was below $30 \%$ and those who returned a survey could not be identified, a second mailing was sent and physicians were asked to return the survey only if they had not responded to the first request. Overall, the response rate following the second mailing was $58 \%$ among members of SGO, and $34.8 \%$ among members of MOG.
The questionnaire queried respondents' views of the effectiveness of various CAM modalities and their approach to each of the modalities in practice. Physicians were asked to rate acupuncture, aromatherapy, bio-electromagnetic therapies, biofeedback, chiropractic intervention, herbal medicine, homeopathy, hypnosis/guided imagery, massage, music therapy, nutritional supplements, prayer/spiritual healing, meditation, psychotherapy, therapeutic/healing touch, movement/physical therapies (e.g. yoga), special diets (e.g. macrobiotic, vegan), and traditional Chinese medicine on a scale ranging from highly effective to harmful. Approach to use of these CAM modalities in practice was scored as: would not recommend; endorse; provide; or refer. In addition, physicians were queried regarding their general attitudes toward CAM. Finally, the questionnaire assessed characteristics of the care providers, including age, gender, ethnicity, degree, and specialty.

Descriptive statistics were used to characterize care providers' demographics, perceptions, and use of CAM modalities in their practice. Three of the scales in the physician survey (e.g. view of effectiveness of CAM modalities, use of CAM approaches in practice, and general attitudes toward (AM) used a 4 to 6point ordinal response format. The effectiveness, approach, and attitude scales comprised 17,18 , and 7 items, respectively. A block score was formed for each scale by averaging the item responses for each subject. A subject's response was considered missing (and hence excluded from the analysis) if more than $25 \%$ of the items were unanswered. Five items under general attitudes were positively framed, with the remaining 2 framed negatively. The latter were reverse coded before calculating the attitude block score so that an overall lower score would be indicative of a positive attitude.

In order to investigate any association between block scores and physician characteristics such as gender, ethnicity (white vs other), specialty (gynecologic oncologist vs other), and age (categorized as <40, 40-50, 50-65, >65 years), we first analyzed each characteristic using a 2-sample $t$ test or a 1 -way ANOVA F test (for age). These univariate analyses were further supplemented by a multiple linear regression analysis

Table 1 Physician demographic characteristics by specialty $(n=462)^{\mathrm{a}}$

\begin{tabular}{lcc}
\hline Characteristics & $\begin{array}{l}\text { Gynecologic oncologists } \\
(n=333)\end{array}$ & $\begin{array}{c}\text { Other oncologists } \\
(n=129)\end{array}$ \\
\hline Gender & & $96(74.4)$ \\
Male & $243(73.0)$ & $28(21.7)$ \\
Female & $76(22.8)$ & $5(3.9)$ \\
Missing & $14(4.2)$ & \\
Ethnicity & & $101(78.3)$ \\
White & $260(78.1)$ & $23(17.8)$ \\
Other & $58(17.4)$ & $5(3.9)$ \\
Missing & $15(4.5)$ & $55.2 \pm 10.4$ \\
Age, y & $48.7 \pm 10.9$ & $110(85.3)$ \\
Degree & & $11(8.5)$ \\
MD & $316(94.9)$ & $4(3.1)$ \\
DO & $4(1.2)$ & $4(3.1)$ \\
Other & $0(0)$ & \\
Missing & $13(3.9)$ & \\
\hline a Values are given as number (percentage) or mean \pm SD. \\
b $P<0.0001$. & & \\
& &
\end{tabular}


Table 2 Physicians' attitudes toward effectiveness and use of complementary and alternative medicine ${ }^{a}$

\begin{tabular}{llll}
\hline Predictors & Effectiveness & Approach & Attitude \\
\hline $\begin{array}{l}\text { Gender } \\
\text { Male }\end{array}$ & $2.95 \pm 0.55^{\mathrm{b}, \mathrm{c}}$ & $1.85 \pm 0.59 \mathrm{~b}, \mathrm{c}$ & $2.47 \pm 0.82^{\mathrm{b}, \mathrm{c}}$ \\
$\begin{array}{l}\text { Female } \\
\begin{array}{l}\text { Specialty } \\
\text { Gynecologic }\end{array}\end{array}$ & $2.76 \pm 0.46^{2}$ & $2.09 \pm 0.52$ & $2.10 \pm 0.67$ \\
$\begin{array}{l}\text { oncology } \\
\text { Medical }\end{array}$ & $3.06 \pm 0.49$ & $1.70 \pm 0.54$ & $2.74 \pm 0.82$ \\
$\begin{array}{l}\text { oncology/ } \\
\text { other }\end{array}$ & & $1.99 \pm 0.58^{\mathrm{b}, \mathrm{c}}$ & $2.25 \pm 0.75^{\mathrm{b}, \mathrm{c}}$ \\
$\begin{array}{l}\text { Ethnicity } \\
\text { White }\end{array}$ & $2.92 \pm 0.53$ & $1.89 \pm 0.57$ & \\
Other & $2.87 \pm 0.59$ & $1.98 \pm 0.63$ & $2.41 \pm 0.81$ \\
\hline
\end{tabular}

${ }^{a}$ Values are given as mean \pm SD for the average block scores.

b $P<0.05$ in an unadjusted comparison via 2-sample $t$ test.

c $P<0.05$ for the corresponding factor in a multivariate linear regression model that adjusts for all predictors shown in the table as well as age.

with block scores as outcomes and all the factors as independent variables. Model diagnostics by means of residual plots exhibited satisfactory conformity to the model assumptions.

Additionally, a dichotomous measure was created from the responses of each of the 7 items under general attitudes scale (coded as 1 for "strongly agree" or "agree" and as 0 otherwise). These dichotomous variables can thus be envisioned as indicator of agreement to the item statement. Logistic regression for each indicator was carried out with gender, ethnicity, specialty, and age as independent variables. The general attitudes of physicians toward CAM were compared by means of 2 -sample $\chi^{2}$ tests of proportion applied to each item.

\section{Results}

A total of 462 physicians completed the survey, including 333 (72.1\%) gynecologic oncologists and 129 (27.9\%) other oncologists (Table 1$)$. The overall response rate was $48 \%$; more gynecologic oncologists (58\%) responded than other oncologists $(34.8 \%)$. Overall, the majority of physicians were white (78.1\%) and male (73.4\%). Most physicians had obtained an MD degree $(92.2 \%)$ and a small proportion had obtained a DO degree (3.3\%). Gynecologic oncologists and other oncologists were similar with respect to gender, ethnicity, and age; however, a higher proportion of gynecologic oncologists (94.9\%) had obtained an MD degree compared with other oncologists (85.3\%) $(P<0.0001)$.

General attitudes among gynecologic oncologists and other oncologists were assessed by providing 7 specific questions regarding physician attitudes toward the role of CAM in conventional medicine. Overall, the majority of physicians reported routinely asking their patients about their use of CAM (77.1\%). As shown in Table 2, female physicians were more likely to have a positive general attitude toward CAM compared with male physicians (mean block score 2.1 vs 2.47, $P<0.05)$. Gynecologic oncologists were more likely to have a positive general attitude toward CAM compared with medical oncologists (mean block score 2.25 vs $2.74, P<0.05$ ) (Table 2 ). Neither ethnicity nor age was a significant predictor of attitude toward CAM. The same overall conclusion ensued when age was used as a continuous covariate in the models.

General attitudes toward CAM were also analyzed by calculating unadjusted and adjusted odds ratios for physician subgroups (gender, specialty, ethnicity, and age) for each of the 7 questions (Table 3). When the analysis was adjusted for other covariates, female physicians and gynecologic oncologists were significantly more likely to believe that clinical care should integrate the best conventional and CAM practices, that CAM includes ideas and methods from which conventional

Table 3 Physicians' attitudes toward complementary and alternative medicine ${ }^{\text {a }}$

\begin{tabular}{|c|c|c|c|}
\hline Attitude components & $\begin{array}{l}\text { Gender } \\
\text { [Ref: female] }\end{array}$ & $\begin{array}{l}\text { Specialty } \\
\text { [Ref: Gyn Onc] }\end{array}$ & $\begin{array}{l}\text { Ethnicity } \\
\text { [Ref: Other] }\end{array}$ \\
\hline $\begin{array}{l}\text { Clinical care should integrate the best } \\
\text { conventional and CAM practices }\end{array}$ & $\begin{array}{l}0.44^{\mathrm{b}} \\
(0.24,0.80)\end{array}$ & $\begin{array}{l}0.25^{\mathrm{b}} \\
(0.15,0.41)\end{array}$ & $\begin{array}{l}0.92 \\
(0.51,1.66)\end{array}$ \\
\hline $\begin{array}{l}\text { CAM includes ideas and methods from which } \\
\text { conventional medicine could benefit }\end{array}$ & $\begin{array}{l}0.34^{\mathrm{b}} \\
(0.18,0.64)\end{array}$ & $\begin{array}{l}0.33^{b} \\
(0.20,0.55)\end{array}$ & $\begin{array}{l}1.01 \\
(0.56,1.84)\end{array}$ \\
\hline $\begin{array}{l}\text { CAM approaches hold promise for treatment of } \\
\text { symptoms, conditions, and/or diseases }\end{array}$ & $\begin{array}{l}0.51^{b} \\
(0.29,0.89)\end{array}$ & $\begin{array}{l}0.47^{\mathrm{b}} \\
(0.29,0.77)\end{array}$ & $\begin{array}{l}0.91 \\
(0.52,1.60)\end{array}$ \\
\hline $\begin{array}{l}\text { Health professionals should be able to advise their } \\
\text { patients about commonly used CAM methods }\end{array}$ & $\begin{array}{l}0.63 \\
(0.36,1.09)\end{array}$ & $\begin{array}{l}0.74 \\
(0.45,1.02)\end{array}$ & $\begin{array}{l}0.92 \\
(0.53,1.61)\end{array}$ \\
\hline Knowledge about CAM is important to me as a patient & $\begin{array}{l}0.70 \\
(0.41,1.19)\end{array}$ & $\begin{array}{l}0.45^{\mathrm{b}} \\
(0.27,0.74)\end{array}$ & $\begin{array}{l}1.57 \\
(0.88,2.80)\end{array}$ \\
\hline $\begin{array}{l}\text { While a few CAM approaches may have limited health } \\
\text { benefits, they have no true impact on treatment of } \\
\text { symptoms, conditions, and/or diseases }\end{array}$ & $\begin{array}{l}3.29^{\mathrm{b}} \\
(1.68,6.42)\end{array}$ & $\begin{array}{l}2.34^{\mathrm{b}} \\
(1.40,3.94)\end{array}$ & $\begin{array}{l}0.88 \\
(0.48,1.62)\end{array}$ \\
\hline CAM is a threat to public health & $\begin{array}{l}4.96^{\mathrm{b}} \\
(1.45,16.91)\end{array}$ & $\begin{array}{l}1.82 \\
(0.87,3.79)\end{array}$ & $\begin{array}{l}1.27 \\
(0.54,2.95)\end{array}$ \\
\hline
\end{tabular}

\footnotetext{
Abbreviastion: CAM, complementary and alternative medicine.

a Values are given as odds ratios (95\% confidence intervals) in favor of the respective attitude components for various subgroups.

b $P<0.05$.
} 
medicine could benefit, and that CAM approaches hold promise for treatment of symptoms, conditions, and/or diseases.

Gynecologic oncologists were also more than twice as likely as the other oncologists to believe that knowledge about CAM is important to them as a patient $(P<0.05)$. Male physicians were 3.3 times more likely $(P<0.05)$ than female physicians to believe that CAM has no true impact on treatment of symptoms, conditions, or diseases. They were also approximately 5 times more likely than their female counterparts to believe that CAM is a threat to public health. Medical and other oncologists were 2.3 times more likely $(P<0.05)$ than the gynecologic oncologists to believe that CAM has no true impact on the treatment of symptoms, conditions, and/or diseases. Neither age nor ethnicity was significantly associated with any of the attitude components.

Physicians were asked their view of the effectiveness of specific CAM modalities. Female physicians and gynecologic oncologists were more likely to believe that CAM modalities were effective compared with male physicians or medical oncologists (mean block score 2.76 and 2.84 for female and gynecologic oncologists, respectively, compared with 2.95 and 3.06 for male or medical oncologists, $P<0.05$ ) (Table 2 ).

Physicians were also asked how they used specific CAM modalities in their practice, and the responses were scored on a 4-point scale, ranging from 1 = "would not recommend" to 4 = "provide." Again, block scores were calculated for each participant (higher overall scores reflect a more favorable response to the use of (AM). In our analyses, female physicians were more likely to endorse or provide CAM compared with male physicians (mean block scores 2.09 and 1.85 , respectively, $P<0.05)$. Similarly, gynecologic oncologists were more likely to endorse or provide CAM compared with medical oncologists (mean block score 1.99 and 1.7, respectively, $P<0.05$ ) (Table 2 ). CAM modalities that were most often rated as highly or moderately effective by all physicians included: massage (59.3\%) and acupuncture (57.4\%). CAM modalities most frequently rated as harmful by physicians included: special diets $(9.7 \%)$, herbal remedies, (7.6\%), chiropractic medicine (7.1\%), homeopathy (5.2\%), and nutritional supplements (3.5\%).

\section{Discussion}

The prevalence of CAM use in the United States ranges between $32 \%$ and $62 \%[1,7]$. CAM use is more common among women [7], and the prevalence of CAM use among cancer patients in the United States overall ranges between $31.4 \%$ and $40 \%[7,18,19]$. Among patients with gynecologic cancers, CAM use has been reported as high as $76.3 \%$ (range, $49.6 \%$ 76.3\%) $[3,4,8]$. Despite the fact that CAM use among gynecologic oncology patients is high, little known is about oncologists' perceptions and attitudes regarding CAM.

Among oncologists surveyed, the majority of physicians (77.1\%) indicated that they routinely ask patients about their use of CAM, and most physicians had a positive general attitude toward CAM. These results are in contrast to other published reports regarding oncologists' attitudes toward CAM, where physicians in Japan, Brazil, Australia, and at the MD Anderson Cancer Center (Texas, USA) had a more negative attitude toward the use of CAM, mainly due to lack of scientific proof of efficacy $[6,9,10,16]$. The majority of physicians surveyed in the present study were gynecologic oncologists; overall, we found that gynecologic oncologists and female providers were more likely to view CAM as effective and have a more positive attitude toward CAM compared with medical oncologists. Oncologists surveyed in other published reports included surgical oncologists, medical oncologists, and radiation oncologists, among others. The discrepancy in physician attitudes toward CAM seen in the present study compared with others may be attributable to gynecologic oncologists having a more positive attitude toward CAM overall, and that the percentage of gynecologic oncologists in other reports was small.

Although most oncologists in the present study reported asking patients about their use of CAM, the responsibility for educating patients about CAM is not routinely embraced by physicians. This sentiment is consistent with previous studies, where many physicians did not feel adequately prepared to counsel patients about their use of CAM [20]. Physicians have limited time to spend with patients, which may contribute toward limited discussion of CAM use. The addition of ancillary care providers or physician-extenders (nurses, nurse practitioners, physician assistants, naturopaths) with expertise regarding CAM therapies to the treatment "team" would undoubtedly enhance quality of care.

The present study is not without limitations. Physician surveys were intentionally kept brief to encourage participation. In order to keep surveys anonymous, we made no effort to keep track of individuals who did and did not participate. The overall percentage of physicians responding (50.3\%) was typical for a nonincentive medical survey, and may indicate a potential for a nonresponse bias.

Although it is imperative that CAM approaches are investigated using rigorous scientific method, until such data are available, these modalities should not be dismissed out of hand. Although all physicians did not have identical views regarding the efficacy of CAM, in general, physicians believe that health care professionals should be able to advise their patients about commonly used CAM modalities. There is a tremendous need for continued public and professional education regarding CAM so that physicians can provide responsible, evidence-based advice to patients seeking CAM therapies.

\section{References}

[1] Eisenberg DM, Davis RB, Ettner SL, Appel S, Wilkey S, Van Rompay $M$, et al. Trends in alternative medicine use in the United States, 1990-1997: results of a follow-up national survey. JAMA 1998;280(18):1569-75.

[2] National Center for Complementary and Alternative Medicine: http: / /nccam.nih.gov.

[3] Swisher EM, Cohn DE, Goff BA, Parham J, Herzog TJ, Rader JS, et al. Use of complementary and alternative medicine among women with gynecologic cancers. Gynecol Oncol 2002;84(3): 363-7.

[4] Von Gruenigen VE, White LJ, Kirven MS, Showalter AL, Hopkins MP, Jenison EL. A comparison of complementary and alternative medicine use by gynecology and gynecologic oncology patients. Int J Gynecol Cancer 2001;11(3):205-9.

[5] Richardson MA, Sanders T, Palmer JL, Greisinger A, Singletary SE. Complementary/alternative medicine use in a comprehensive cancer center and the implications for oncology. J Clin Oncol 2000;18(13):2505-14.

[6] Hyodo I, Eguchi K, Nishina T, Endo H, Tanimizu M, Mikami I, et al. Perceptions and attitudes of clinical oncologists on 
complementary and alternative medicine: a nationwide survey in Japan. Cancer 2003;97(11):2861-8.

[7] Barnes PM, Powell-Griner E, McFann K, Nahin RL. Complementary and alternative medicine use among adults: United States, 2002. Adv Data 2004;343:1-19.

[8] McKay DJ, Bentley JR, Grimshaw RN. Complementary and alternative medicine in gynaecologic oncology. J Obstet Gynaecol Can 2005;27(6):562-8.

[9] Samano ES, Ribeiro LM, Campos AS, Lewin F, Filho ES, Goldenstein PT, et al. Use of complementary and alternative medicine by Brazilian oncologists. Eur J Cancer Care (Engl) 2005;14(2):143-8.

[10] Richardson MA, Masse LC, Nanny K, Sanders C. Discrepant views of oncologists and cancer patients on complementary/alternative medicine. Support Care Cancer 2004;12(11):797-804.

[11] Richardson MA, Straus SE. Complementary and alternative medicine: opportunities and challenges for cancer management and research. Semin Oncol 2002;29(6):531-45.

[12] Molassiotis A, Sylt P, Diggins $H$. The management of cancerrelated fatigue after chemotherapy with acupuncture and acupressure: A randomised controlled trial. Complement Ther Med 2007;15(4):228-37.

[13] Lagman R, Walsh D. Dangerous nutrition? Calcium, vitamin D, and shark cartilage nutritional supplements and cancer-related hypercalcemia. Support Care Cancer 2003;11(4):232-5.
[14] Kligler B, Maizes V, Schachter S, Park CM, Gaudet T, Benn R, et al. Core competencies in integrative medicine for medical school curricula: a proposal. Acad Med 2004;79(6):521-31.

[15] Jump J, Yarbrough L, Kilpatrick S, Cable T. Physicians' attitudes toward complementary and alternative medicine. Integr Med 1998;1(4):149-53.

[16] Newell S, Sanson-Fisher RW. Australian oncologists' self-reported knowledge and attitudes about non-traditional therapies used by cancer patients. Med J Aust 2000;172(3):110-3.

[17] Lee SI, Khang YH, Lee MS, Kang W. Knowledge of, attitudes toward, and experience of complementary and alternative medicine in Western medicine- and oriental medicine-trained physicians in Korea. Am J Public Health 2002;92(12):1994-2000.

[18] Ernst E, Cassileth BR. The prevalence of complementary/ alternative medicine in cancer: a systematic review. Cancer 1998;83(4):777-82.

[19] Mao JJ, Farrar JT, Xie SX, Bowman MA, Armstrong K. Use of complementary and alternative medicine and prayer among a national sample of cancer survivors compared to other populations without cancer. Complement Ther Med 2007;15(1):21-9.

[20] Wahner-Roedler DL, Vincent A, Elkin PL, Loehrer LL, Cha SS, Bauer BA. Physicians' attitudes toward complementary and alternative medicine and their knowledge of specific therapies: a survey at an academic medical center. Evid Based Complement Alternat Med 2006;3(4):495-501. 